\title{
Optimizing Throughput, WIP, and Cycle Time: A Case Study of Utensils Manufacturing Shop Floor
}

\author{
Muhammad Shafiq*, Muhammad Waqas, Khurram Shahzad, Zahid Rashid, Abid Ali, Muhammad Awais \\ Islam, Muhammad Bilal and Usman Hameed \\ *Department of Industrial Engineering, University of Engineering and Technology Taxila, Pakistan \\ **Industrial Engineering and Management, Institute of Quality and Technology Management, University of the Punjab, Lahore, Pakistan \\ *Corresponding Author: shafiqaatir1@gmail.com
}

\begin{abstract}
The development of simulation models for improving performances is trendy in manufacturing industries. This paper presents simulation model for evaluating and improving performances of a utensils manufacturing plant. Internal benchmarking is employed for comparison under exactly similar conditions. The data of all input variables is collected and statistical models for each process is developed using Arena input analyzer. The simulation model is then developed using SIMIO to optimize throughput, work-in-process, and cycle time. The experiments have been performed under various scenarios, i.e., at different values of the input parameters. The areas for improvement have been highlighted on the basis of results. Furthermore, best and worst case scenarios have been discussed in detail to provide insights for managerial performance improvements by (1) optimizing inter-arrival time, (2) increasing production rate, and (3) reducing the number of rejected parts without disturbing the existing setup of the manufacturing facility.
\end{abstract}

Keywords: Shop floor; Utensils manufacturing; Throughput; Work-in-process; Cycle time; Optimization.

\section{INTRODUCTION}

The use of simulation modeling is increasing for solving healthcare, manufacturing, and supply chain problems (Dehghanimohammadabadi \& Keyser, 2017, Barenji et al., 2016). The useful tools for the practitioners and researchers to perform experimentation without disturbing operations include statistics, lean six-sigma, mathematical modeling, and simulation (Galankashi et al., 2016, Habidin et al., 2016, Silva et al., 2015, Tako \& Kotiadis 2015, Galankashi et al., 2013). However, the development of simulation models of real world problems and then solving using DOE techniques are challenging (Amiri \& Mohtashami 2012, Ajdari \& Mahlooji, 2014). Manufacturing systems are backbone of the industry; hence, planning, scheduling, and operational problems of these systems are becoming increasingly important (Geyik \& Dosdoğru, 2013).

The improvements in shop floor of manufacturing and processing come as a result of thorough examination of the problems and experimentation (Marco, 1996). Improvement in throughput has been ultimate priority for most of the industries. Bukchin \& Cohen (2013) suggested a workload sharing mechanism in which experienced workers share part of the workload of less experienced workers. Generally, the factories contain heavy machines such as hydraulic press, roller mills, ball mills, crushers, and series of other machines for various processes required to manufacture products. Once the setup is fixed and becomes operational, any kind of experimentation and change is difficult and has impact on production, lead time, and cost (Chandra \& Nadir, 2013, Hon \& Serna, 2005). The real time experimentation may cause huge losses in terms of cost, equipment, and time in shop floors where the facilities are fixed (Danny, 2003, Chandra \& Nadir, 2013). Also, the owners may not be in favor of experimentation. In such cases, mathematical programming and simulation models are helpful for experimentation rather changing the existing setup again and again (Dehghanimohammadabadi \& Keyser, 2017, Ali \& Kursad, 2003). The market demand of the kitchen utensils is growing day by day, resulting in an increased pressure on utensils manufacturing factories to meet customers' need 
and expectations. In such cases, the need of the performance analysis to find out potential improvement areas has become critical (Wright \& Osborne, 2005, Sanjay \& Triantis, 2011).

Discrete-event simulation is prevalent and has been used for reducing the planning and waiting time for surgical procedures in medical field (Werker et al., 2009, Villamizar et al., 2011). Indeed, the clinical activities have been reorganized in a way that the patient's waiting time is reduced. Catherine (1997) integrated discrete event simulation and genetic algorithm to optimize job shop scheduling. Antuela \& Stewart (2012) used Discrete Event Simulation and System Dynamics as decision tools to optimize operations of logistics and supply chain management. Thomas \& Lars (2014) introduced simulation-based framework that allows for modeling the behavior of the market demand and the production system. Savsar \& Al-Jawini (1995) developed simulation models to find out the effects of demand variability, line length, kanban system, and random processing time on WIP inventory, throughput, and station utilization. In another study, Savsar (1996) developed simulation model to find out the effect of kanban withdrawal policies on performance measures such as total WIP inventory, throughput, and station utilization. Similarly, Savsar \& Abdulmalek (2008) simulated a pull-push assembly line system to minimize costs occurred due to demand delay and inventory. Lacksonen (2001) compared the performance of search algorithms including Hooke-Jeeves pattern, Nelder-Mead simplex, simulated-annealing, and genetic-algorithm for four simulation based industrial case studies. Doug \& Saeid (2003) used discrete event simulation on a casting facility to identify robust operating regions through selection of controllable factory variables. Spedding \& Sun (1999) used discrete event simulation to evaluate the activity based costing (ABC) of a manufacturing facility. James (2013) used simulation optimization for semiconductor assembly in order to improve productivity. The simulation of CONWIP was experimented for wafer fabrication by Nur et al. (2015), and results showed that batching outperformed the non-batching systems.

Productivity improvement has gained considerable importance of the researchers and practitioners. It has been well established that the importance of the productivity is independent of the size of the enterprise and scope of this importance covers service as well as manufacturing industries (Chiang et al., 2013). For instance, Chen (2014) implemented productivity improvement to stock management system under backlogging and observed an increased profit. Small enterprises and local factories working in Pakistan mostly lack any smart system to calculate waste and performances in terms of productivity such as throughput rate, cycle-time, and work-in-process level. Because of these problems, manufacturing lead time of the process increases, resulting in higher defective and rejected parts, making it difficult to implement lean manufacturing (Kearney, 2015, Kumar \& Wayne, 2006). The main focus of this study is to optimize throughput, WIP, and cycle time in manufacturing industries. For this purpose, a local Kitchen utensils manufacturing factory at Hattar-Pakistan has been selected consisting of heavy machines such as furnace, rolling, cutting, and spindle. In Pakistan, medium enterprises usually do not have any criteria or method of measuring scrap, rejections, work in process (WIP), throughput rate, bottleneck rate, and other such parameters, which are important in process analysis and improvement (Jelena \& Dragan, 2014, Kinjal \& Vivek, 2014). In such scenarios, simulation techniques are helpful where rapid experimentation can be done to find out the results of the proposed experiments with different process parameters such as throughput, work-in-process, and cycle-time.

The main focus of this paper is to analyze and improve performance of the existing shop floor setup of a kitchen utensils manufacturing facility. Hence, a simulation model is developed for identification of bottleneck station and possible improvements using internal benchmarking. Simulation technique is selected as it is difficult to carry out experiments in reality and possible outcomes are achieved without disturbing any operation or facility. The main objective of this paper is to develop simulation model using Arena and Simio in order to analyze progress using internal bench marking techniques. The optimized results are found through experimentation at various levels of interarrival time, cycle time, throughput, and WIP.

The management of the remaining sections of this paper is as follows. Section 2 presents details of internal benchmarking. Section 3 contains details of the simulation model. Section 4 comprises results and discussion. Section 5 discusses improvements made through simulation. Finally, conclusions and recommendations for future work are presented in section 6 . 


\section{INTERNAL BENCHMARKING}

Performance evaluation requires a baseline and/or standard for comparison. A comparison of a manufacturing facility with another facility may not be a good idea as both may not have the same value of the parameters affecting performances of the facility. Internal benchmarking addresses this issue by comparing actual performance with theoretical (simulated) output of the same manufacturing facility (Mark \& Jeffrey, 2005). In this regard, the main performance measuring parameters used in internal benchmarking are (1) throughput (TH), (2) cycle-time (CT)/flowtime, and (3) work-in-process (WIP). Throughput is the average output per unit time. The inventory between starting and ending points of a production system is called work-in-process. The cycle-time of a given production system is defined as the average time parts spend as work-in-process (Chandra \& Nadir, 2013, Kinjal \& Vivek, 2014). The abovementioned performance measuring parameters are manipulated by bottleneck rate $\left(\mathrm{r}_{\mathrm{b}}\right)$, raw process time $\left(\mathrm{T}_{\mathrm{o}}\right)$, and the critical WIP $\left(\mathrm{W}_{\mathrm{o}}\right.$ ). The bottleneck rate is the production rate of the bottleneck station (a station taking the longest time for processing or the station, which is producing least number of parts per unit time).

Raw processing time $\left(\mathrm{T}_{\mathrm{o}}\right)$ is equal to the time taken by all the processes without delay at any stage. The critical WIP is the minimum WIP level required for the given raw process time at maximum throughput of the bottlenecks. WIP level can be computed for given values of Throughput and Cycle time using Little's law, i.e., $L=\lambda W$, or in modified form $W I P=T H \times C T$ (Jewell, 1967). It should be noted that this formula does not provide precise results when there is variability in line; i.e., when the process times are not constant, instead probability distributions are used. The theoretical best case is obtained through extension in little's law for manufacturing facility.

$$
C T \geq C T_{\text {best }}=\left\{\begin{array}{ll}
T_{o} & \text { if } w \leq W_{o} \\
w / r_{b} & \text { if } w>W
\end{array}\right\}
$$

And for maximum throughput,

$$
T H \leq T H_{\text {best }}=\left\{\begin{array}{ll}
w / T_{o} & \text { if } w \leq W_{o} \\
r_{b} & \text { if } w>W
\end{array}\right\}
$$

$w$ : Current WIP level

$r_{b}$ : Bottleneck rate

\section{Wo: Critical WIP level}

From equations (1) \& (2), the best cycle time and throughput can be computed. If bottleneck rate " $r_{b}$ " is increased, it would lead to increase in " $C T$ " and " $T H$ " when "WIP" is more than "Wo". Decrease in "To" improves " $C T$ " and " $T H$ " when "WIP" is below "Wo". In general, the improvements can be made by increasing processing rate of the bottleneck workstations, to the point that all workstations are balanced.

To find out the cycle time and the throughput under worst case at the utensils manufacturing, whenever a job is finished, it is removed from its pallet. The pallet is then immediately returned to the front of the line to carry a new job. In this way, the WIP is kept constant, but queue of the parts is produced in front of each workstation. In order to distribute the region into good and bad, theoretical worst performance, which is also known as bottom line performance, should be known and is calculated using the following formula.

$$
C T \leq C T_{\text {worst }}=w T o
$$

and

$$
T H \geq T H_{\text {worst }}=1 / T o
$$

It should be noted that these are theoretical best and worst parameters; no production line in actual behaves like this. Therefore, an intermediate case is developed as extension of little law, which is termed as practical worst case 
(PWC). It can be seen that, under exponential distribution, cycle-time, and throughput are explained as

$C T=T o+(w-1) / r_{b}$

And, the throughput for PWC is given by

$T H=w r_{b} /(W o+w-1)$

where "To" is the raw process time, " $w$ " is the current WIP level, " $r_{b}$ " is the bottleneck rate

For $N$ number of work stations,

$C T=T_{o}(1+(w-1) / N)$ and,

$T H=w / C T=w r_{b} /(W o+w-1)$

If the performance of a system is between the best case and the practical worst case, then the system is managed effectively. The above-defined optimal functions are applied on the Utensils manufacturing to optimize cycle time and throughput functions. The performance of the system at the plant is found to be between the practical worst case and the worst case. Hence, significant opportunities for improvements are available.

As three parameters with their extremes and an intermediate case are developed, we can define the good and bad regions by plotting the graphs of " $T H$ " versus "WIP" and "CT" versus "WIP" for the three cases. Generic trends showing the good (lean) and bad (fat) regions are shown in Figure 1.

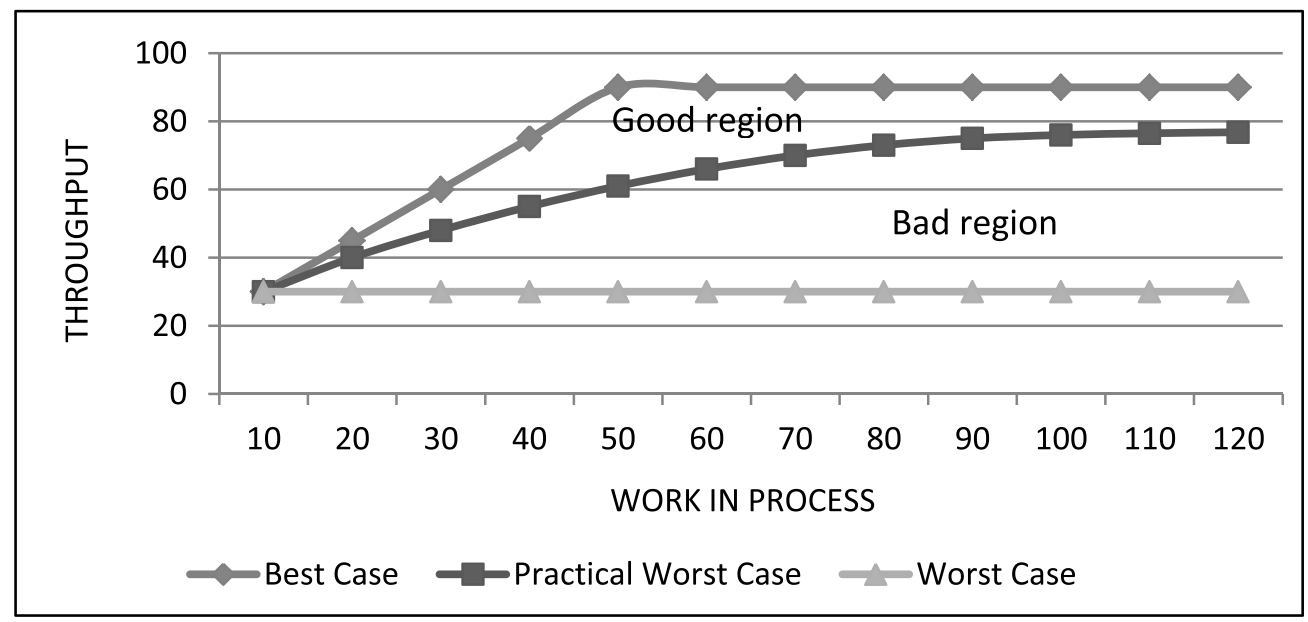

Figure 1. Throughput vs. work-in-process (Good and Bad regions).

It can be seen from Figure 1 that there are two regions. If a factory lies in a good region, it means that there is little or no chance for further improvement with existing facilities or in other words, the plant is lean and efficient. On the other hand, if a factory lies in a bad region, it means chances of improvement are there. Like, implementation of kanban system minimizes lead time and inventory on floor and optimizes storage area (Naufal et al., 2012). Iwata \& Mavris (2012) developed virtual environment for operations and support process simulation, which aimed to support future research activities in logistics operations design and maintenance. Another algorithm is developed by Lee \& Lee (1997) for balancing the lane capacity usage even in lane blocking situation. Simulation results of this algorithm were found to be in good agreement with practical scenarios. 


\section{THE METHODOLOGY}

Simulation model is developed for a utensils manufacturing plant (Najam Utensils) located at Hattar Haripur, Pakistan. The factory produces teapots and cooking pots with variety of designs and sizes. It started its operation in 2007 and currently producing kitchen utensils with an average output of $3000 \mathrm{Kg}$ per day ( 24 hours). The raw material comprises useable items of steel in various forms. The sequence of the processes to make utensils is given in Table 1 and elaborated in Figure 2. The factory works 24 hours a day.

Table 1. Sequence of the Processes.

\begin{tabular}{|c|c|}
\hline Sequence & Process \\
\hline 1 & Raw material Moved through manual trolley \\
\hline 2 & Furnace \\
\hline 3 & Manual pouring in dies \\
\hline 4 & Casting \\
\hline 5 & Moved through manual trolley \\
\hline 6 & Roll Mill \\
\hline 7 & Moved through manual trolley \\
\hline 8 & Or Roll Mill 2 \\
\hline 9 & Moved through manual trolley \\
\hline 10 & Annealing process \\
\hline 11 & Moved through manual workers \\
\hline 12 & Rectangular Cutting process \\
\hline 13 & Circular cutting process \\
\hline 14 & Moved through manual transport \\
\hline 15 & Spindle machine \\
\hline 16 & Assembly \\
\hline
\end{tabular}




\section{Manufacturing Process and Layout Explanation}

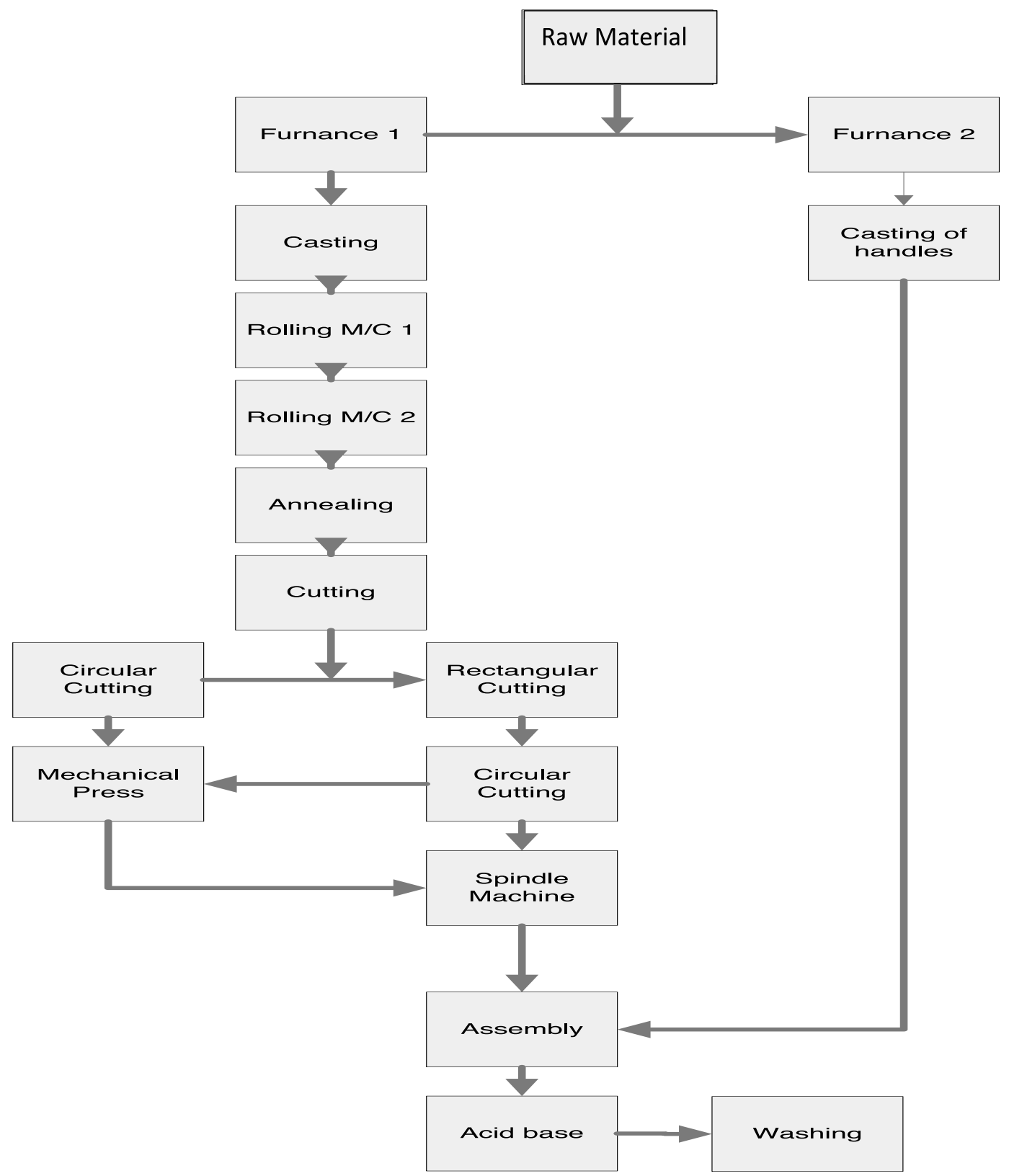

Figure 2. Process Flow Chart.

The raw material for the kitchen utensils manufacturing is in various forms of iron. While conducting this study, it has been assumed that the raw material is in the form of iron scrap. At first, raw material is fed into two furnaces; one furnace is related to casting of main parts and the other furnace is dedicated for casting process of accessories like handles. The main part casting material is forwarded to Rolling machine 1 and Rolling machine 2. After rolling process, annealing process is being done for 24 hours. The material is then forwarded to the cutting section where circular or rectangular cutting is done following the requirements. After cutting process, parts are forwarded to the mechanical press section for taking required shape of the desired utensil, i.e., cooking pot, tea pot, or bowl. It is then 
forwarded to the spindle machine section for finishing part shaping process, and then to the assembly section for assembling of parts and accessories. The last process is acid base electrolysis and washing. The parts are transported through manual means by workers from one station to the other.

\section{Model Development}

The simulation model developed using SIMIO is shown in Figure 3. The limitation of the developed simulation model is that it does enclose certain steps combined or a single step separated into two parts for the sake of ease.

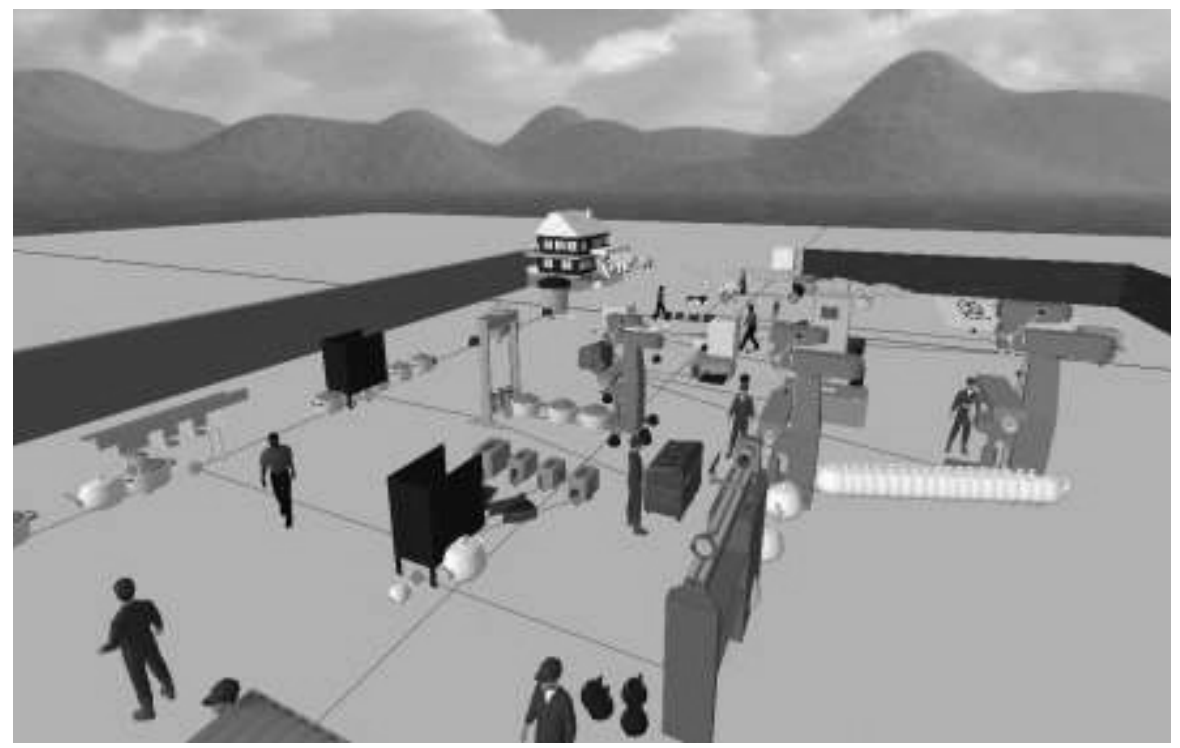

Figure 3. SIMIO Model (Najam Khyber Metals).

The time study for all processes is done on numerous occasions to get better results. The sequence of the events with the respective process time and distribution summary is given in Table 2. The data is taken for two types of utensils, i.e., teapot and cooking pot, to check versatility and effectiveness of the model. Both pots are considered to be of similar size and material. So, all the processes take similar time for both parts except assembly operation.

Table 2. Sequence of the Processes with Time Study Data.

\begin{tabular}{|c|c|c|}
\hline Process & Time (50 readings) & Distribution Summary \\
\hline \multirow{3}{*}{ Casting } & \multirow{3}{*}{ 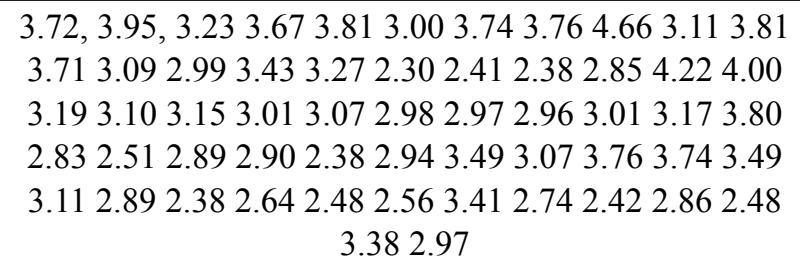 } & Distribution: Weibull \\
\hline & & $\begin{array}{c}\text { Expression: } 2.06+\text { WEIB } \\
(1.24,2.25)\end{array}$ \\
\hline & & Square Error: 0.04 \\
\hline \multirow{3}{*}{ Roll mill } & \multirow{3}{*}{ 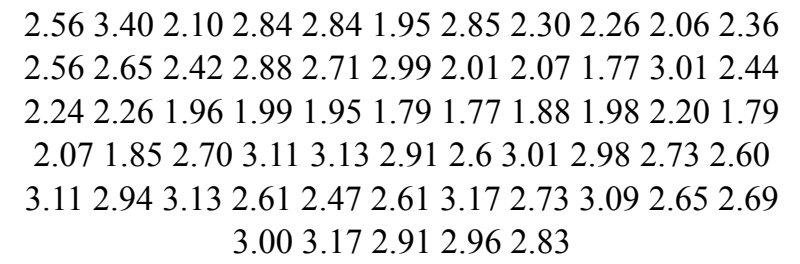 } & Distribution: Beta \\
\hline & & $\begin{array}{c}\text { Expression: } 1.6+1.97 * \\
\text { BETA }(1.8,1.96)\end{array}$ \\
\hline & & Square Error: 0.01 \\
\hline
\end{tabular}


3.354 .694 .544 .253 .263 .603 .964 .474 .293 .623 .95

Circular/Rectangular cutting

Mechanical press

Spindle

Assembly of cooking pot

Assembly of tea pot

Acid base process

Washing

3.973 .673 .554 .444 .364 .273 .934 .403 .693 .363 .64 3.373 .043 .584 .274 .134 .433 .593 .653 .814 .004 .46 2.792 .793 .803 .793 .085 .054 .534 .483 .983 .694 .44 4.173 .333 .673 .533 .773 .03

17.1011 .9613 .2513 .0113 .7312 .7312 .5013 .0112 .94 11.1212 .7813 .0613 .0611 .0812 .0616 .5012 .0413 .78 12.1212 .9812 .5312 .2211 .9611 .2911 .4013 .8912 .23 12.9913 .0512 .4313 .2613 .5612 .2811 .3314 .5313 .01 14.0912 .3814 .2613 .1314 .6612 .7714 .2912 .9713 .69 14.0112 .6612 .5414 .0911 .6614 .0912 .8613 .9516 .02

60.1861 .6959 .5554 .5163 .5962 .0561 .5559 .8963 .43 61.0360 .6959 .8458 .8157 .6359 .3163 .4466 .0167 .33 66.8868 .3166 .3963 .2162 .0167 .8961 .1060 .0558 .09 59.5460 .0160 .0568 .9169 .0059 .9460 .3267 .4165 .98 58.0961 .1165 .5568 .0959 .7861 .2966 .6769 .0963 .01 63.5659 .1258 .0165 .0566 .9069 .2760 .0367 .7761 .44 67.9064 .1265 .0068 .0869 .1258 .8863 .2965 .12

17.0118 .9222 .3321 .9217 .9518 .6619 .3218 .9921 .37 22.9223 .1023 .0122 .6721 .2920 .2521 .2423 .6716 .95 18.3621 .0522 .1921 .3123 .6123 .1121 .6322 .1921 .65 22.3321 .6522 .6318 .1918 .2322 .0019 .3720 .0119 .43 19.9718 .7722 .6523 .01

30.5928 .2631 .5332 .4128 .7129 .3329 .3330 .0030 .59 33.4430 .5329 .6533 .6229 .9930 .0122 .2122 .1333 .95 32.1033 .5629 .1128 .9928 .6931 .6633 .3331 .5927 .36 30.3332 .5933 .6632 .1232 .1330 .6927 .3327 .6729 .12 29.9928 .3233 .0132 .1632 .3228 .6327 .3329 .4529 .86 30.0029 .4631 .2233 .1728 .8829 .13

25.9223 .7824 .8521 .2320 .6624 .4123 .3322 .2123 .31 22.2623 .5321 .6921 .7022 .5523 .6723 .3222 .6521 .19 22.4424 .1024 .4823 .0122 .6422 .4424 .1223 .9922 .43 21.6723 .4223 .4221 .9822 .5523 .66

7.707 .767 .838 .619 .037 .567 .716 .937 .187 .336 .14 5.195 .726 .967 .225 .857 .028 .117 .256 .396 .677 .54 7.326 .976 .546 .598 .218 .657 .339 .007 .126 .157 .30 6.326 .596 .097 .687 .246 .937 .336 .12
Distribution: Beta Expression: $2.56+2.72 *$ BETA $(3.19,3.48)$

Square Error: 0.02

Distribution: Normal Expression: NORM (13.1, 1.22)

Square Error: 0.01

Distribution: Gamma

Expression: 54 + GAMM (1.92, 4.72)

Square Error: 0.02

Distribution: Beta Expression: $16.3+7.73 *$ BETA $(1.7,1.16)$ Square Error: 0.01

\begin{tabular}{c} 
Distribution: Normal \\
\hline Expression: NORM \\
$(30.2,2.46)$ \\
\hline Square Error: 0.02 \\
\hline
\end{tabular}

Distribution: Beta Expression: $20.1+5.87$ * BETA $(2.64,2.78)$ Square Error: 0.0005

\begin{tabular}{c} 
Distribution: Normal \\
\hline Expression: NORM \\
$(7.15,0.856)$ \\
\hline Square Error: 0.009
\end{tabular}




\section{RESULTS AND DISCUSSION}

After data modeling in SIMIO, 200 simulation runs have been conducted to compare important parameters such as throughput (TH) (without downtime), cycle time (CT), work in process (WIP), and material wastage (number of teapots or cooking pots rejected). The number of simulation runs has been decided after half width error analysis. Firstly, the teapot is studied for the best case, worst case, and the practical worst case, and then the cooking pot is analyzed for possible improvements. From validation and verification, the developed model was found ready for testing.

\section{TEA POT}

Table 3. Results of WIP, Bottleneck rate, and CT for Best Case Scenario

\begin{tabular}{ccccl}
\hline $\begin{array}{c}\text { Inter-arrival } \\
\text { time (min) }\end{array}$ & WIP & Rb & $\begin{array}{c}\text { CT best } \\
(\text { min) }\end{array}$ & \\
\hline 0 & 32493.88 & 97 & 334.99 & \\
1 & 27099.06 & 97 & 279.37 & \\
5 & 3799.48 & 97 & 39.17 & $C T(\mathrm{BEST})=W / r_{b}$ \\
10 & 1389.87 & 97 & 14.33 & \\
15 & 530.94 & 97 & 5.47 & \\
16 & 466.80 & 97 & 5.3 & \\
17 & 381.89 & 97 & 5.3 & \\
18 & 432.62 & 97 & 5.3 & \\
19 & 445.93 & 97 & 5.3 & \\
20 & 522.16 & 97 & 5.3 & \\
25 & 424.40 & 97 & 5.3 & \\
30 & 255.03 & 97 & 5.3 & \\
\hline
\end{tabular}

By running Simio model at various levels of inter-arrival time, the values of $W I P$, bottleneck rate, and cycle time are collected, which are shown in Table 3. It can be seen that cycle time is directly proportional to WIP; i.e., the increase in WIP increases cycle time. However, the increase in inter-arrival time decreases both WIP and cycle time. The experiments are also performed to find out the relationship between work-in-process $(W I P)$ and throughput $(T H)$. The results at various levels of inter-arrival time are given in Table 4.

Table 4. Results of WIP, Inter arrival time, and TH for Best Case Scenario.

\begin{tabular}{cccccc}
\hline $\boldsymbol{I} \boldsymbol{A}(\boldsymbol{m i n})$ & $\boldsymbol{W I P}$ & $\boldsymbol{T o}(\boldsymbol{m i n})$ & $\boldsymbol{W}_{\boldsymbol{0}}=\boldsymbol{r}_{\boldsymbol{b}} \times \boldsymbol{T}_{\boldsymbol{\theta}}$ & $\boldsymbol{T H}$ best & \\
\hline 0 & 32493.88 & 5.30 & 514.10 & 97.00 & \\
1 & 27099.06 & 5.30 & 514.10 & 97.00 & \\
5 & 3799.48 & 5.30 & 514.10 & 97.00 & $W>W_{0}$ \\
10 & 1389.87 & 5.30 & 514.10 & 97.00 & \\
15 & 530.94 & 5.30 & 514.10 & 97.00 & \\
16 & 466.80 & 5.30 & 514.10 & 88.08 & \\
17 & 381.89 & 5.30 & 514.10 & 98.52 & \\
18 & 432.62 & 5.30 & 514.10 & 80.08 & \\
19 & 445.93 & 5.30 & 514.10 & 48.12 & $W \leq W_{0}$ \\
20 & 522.16 & 5.30 & 514.10 & 56.26 & \\
25 & 424.40 & 5.30 & 514.10 & 55.56 & \\
30 & 255.03 & 5.30 & 514.10 & 37.92 & \\
\hline
\end{tabular}




\section{Worst case}

Table 5. Result of WIP, TH and CT for Worst Case.

\begin{tabular}{cccc}
\hline IA & WIP & TH worst & CT worst \\
\hline 0 & 32493.88 & 0.19 & 172217.60 \\
1 & 27099.06 & 0.19 & 143625.00 \\
5 & 3799.48 & 0.19 & 20137.24 \\
10 & 1389.87 & 0.19 & 7366.34 \\
15 & 530.94 & 0.19 & 2813.97 \\
16 & 466.80 & 0.19 & 2474.03 \\
17 & 381.89 & 0.19 & 2767.45 \\
18 & 432.62 & 0.19 & 2249.34 \\
19 & 445.93 & 0.19 & 1351.68 \\
20 & 522.16 & 0.19 & 1580.42 \\
25 & 424.40 & 0.19 & 1560.66 \\
30 & 255.03 & 0.19 & 1065.30 \\
\hline
\end{tabular}

The results of the worst case scenario are presented in Table 5. Table 5 demonstrates that throughput (worst) remains the same at various levels of inter-arrival time. However, the value of WIP does not remain the same and decreases by increasing inter-arrival time. The value of the cycle time and WIP decreased by increasing inter-arrival time.

\section{Practical worst case}

The results of practical worst case scenario are shown in Table 6. It has been observed that throughput increases with increase in work-in-process; however, after a certain level there is no significant increment. Hence, there is no need to build up inventory after that.

Table 6. Result for Practical Worst case.

\begin{tabular}{cccccc}
\hline $\mathbf{W I P}$ & $\mathbf{T}_{\mathbf{o}}$ & $\mathbf{r}_{\mathbf{b}}$ & $\mathbf{C T}_{\mathbf{p w c}}$ & $\mathbf{W}_{\mathbf{o}}$ & $\mathbf{T H}_{\mathbf{p w c}}$ \\
\hline 32493.88 & 5.30 & 97 & 340.28 & 514.10 & 95.49 \\
27099.06 & 5.30 & 97 & 284.66 & 514.10 & 95.20 \\
3799.48 & 5.30 & 97 & 44.46 & 514.10 & 85.46 \\
1389.88 & 5.30 & 97 & 19.62 & 514.10 & 70.84 \\
530.94 & 5.30 & 97 & 10.76 & 514.10 & 49.33 \\
466.80 & 5.30 & 97 & 10.10 & 514.10 & 46.21 \\
381.89 & 5.30 & 97 & 10.67 & 514.10 & 48.92 \\
432.62 & 5.30 & 97 & 9.66 & 514.10 & 43.91 \\
445.93 & 5.30 & 97 & 7.92 & 514.10 & 32.21 \\
522.16 & 5.30 & 97 & 8.36 & 514.10 & 35.65 \\
424.40 & 5.30 & 97 & 8.32 & 514.10 & 35.37 \\
255.03 & 5.30 & 97 & 7.36 & 514.10 & 27.30 \\
\hline
\end{tabular}


Our target is to achieve maximum throughput with minimum cycle-time and work-in-process to optimize manufacturing processes. Teapot is analyzed under the best-case, worst-case, and practical-worst-case scenarios. The inter-arrival time is a key parameter, which controls other process parameters. It is found that 15 minutes is the best inter arrival time for each bath where the critical values of work-in-process, cycle-time, and throughput are achieved. Furthermore, cycle time is directly proportional to the work in process in all three cases. The change in cycle time and throughput performance with respect to work-in-process is shown in Figure 4.
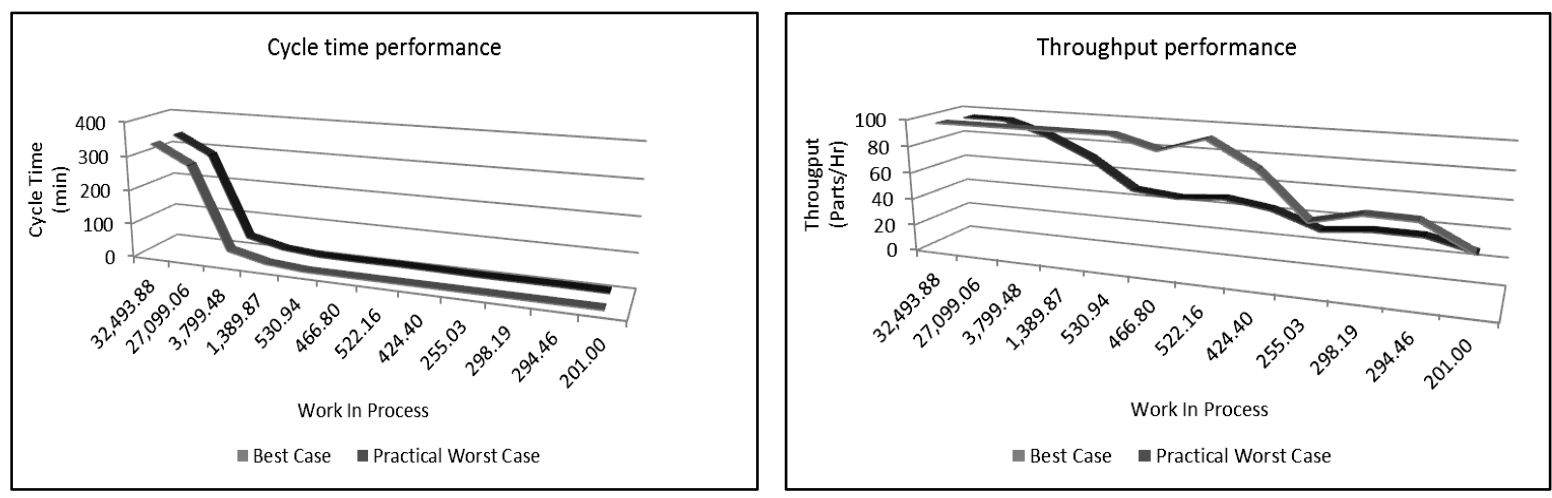

Figure 4. Change in cycle time and throughput performances for teapot.

\section{COOKING POT}

\section{Best case}

By running Simio model at various levels of inter-arrival time, the values of the parameters are collected, which are shown in Table 7. It can be seen that "WIP" is directly proportional to the cycle time; i.e., the increase in "WIP" increases cycle time and vice-versa. However, the increase in inter-arrival time decreases both cycle time and "WIP". The same observation has been found in best case of the teapot.

Table 7. Result for Best Case of Cooking Pot.

\begin{tabular}{|c|c|c|c|}
\hline WIP & $r_{b}$ & CT BEST & \\
\hline 25108 & 172 & 145.98 & \multirow{5}{*}{ 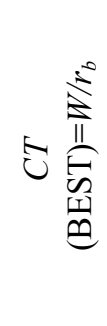 } \\
\hline 21358 & 172 & 124.17 & \\
\hline 15893 & 172 & 92.40 & \\
\hline 2106 & 172 & 12.24 & \\
\hline 614 & 172 & 3.57 & \\
\hline 460 & 172 & 2.60 & \multirow{5}{*}{ 厄) } \\
\hline 401 & 172 & 2.60 & \\
\hline 335 & 172 & 2.60 & \\
\hline 227 & 172 & 2.60 & \\
\hline 199 & 172 & 2.60 & \\
\hline
\end{tabular}


The experiments are also performed to find out the relation between "WIP" and throughput (TH). The results of the experiments at various levels of inter-arrival time are given in Table 8 . The relationship between "WIP” and throughput $(\mathrm{TH})$ at various levels of inter-arrival time shows that the increase in work-in-process increases production rate up to a certain limit. Hence, maximum throughput is possible with controlled inventory (work-in-process).

Table 8. TH VS WIP (Best case).

\begin{tabular}{|c|c|c|c|c|}
\hline WIP & $\mathbf{T}_{o}$ & $\mathbf{W}_{\mathrm{O}}=\mathbf{R}_{\mathrm{B}} \times \mathbf{T}_{\mathrm{O}}$ & TH Best & \\
\hline 25108 & 2.60 & 447.20 & 172.00 & \multirow{5}{*}{$\begin{array}{l}\stackrel{ }{\wedge} \\
\triangleq\end{array}$} \\
\hline 21358 & 2.60 & 447.20 & 172.00 & \\
\hline 15893 & 2.60 & 447.20 & 172.00 & \\
\hline 2106 & 2.60 & 447.20 & 172.00 & \\
\hline 614 & 2.60 & 447.20 & 172.00 & \\
\hline 460 & 2.60 & 447.20 & 176.92 & \multirow{5}{*}{$\frac{D}{V}$} \\
\hline 401 & 2.60 & 447.20 & 154.23 & \\
\hline 335 & 2.60 & 447.20 & 128.85 & \\
\hline 227 & 2.60 & 447.20 & 87.31 & \\
\hline 199 & 2.60 & 447.20 & 76.54 & \\
\hline
\end{tabular}

\section{Worst case}

The relationship of "WIP" with throughput and cycle time for worst case is given in Table 9. It can be seen from table 9 that throughput (worst) remains the same at various levels of inter-arrival time. However, the value of "WIP" does not remain the same by increasing inter-arrival time.

Table 9. The Relationship among WIP, Cycle Time (worst), and TH (worst).

\begin{tabular}{cccc}
\hline WIP & To & CT $_{\text {worst case }}$ & TH $_{\text {worst case }}$ \\
\hline 25108 & 2.60 & 65280.80 & 0.005 \\
21358 & 2.60 & 55530.80 & 0.005 \\
15893 & 2.60 & 41321.80 & 0.005 \\
2106 & 2.60 & 5475.60 & 0.005 \\
614 & 2.60 & 1596.40 & 0.005 \\
460 & 2.60 & 1196.00 & 0.005 \\
401 & 2.60 & 1042.60 & 0.005 \\
335 & 2.60 & 871.00 & 0.005 \\
227 & 2.60 & 590.20 & 0.005 \\
199 & 2.60 & 517.40 & 0.005 \\
\hline
\end{tabular}




\section{Practical worst case}

The results of the cooking pot for practical worst case scenario are shown in Table 10.

Table 10. The relationship of WIP, CT (PWC) and TH (PWC).

\begin{tabular}{cccccc}
\hline WIP & $\mathbf{T}_{\mathbf{0}}$ & $\mathbf{r}_{\mathbf{b}}$ & $\mathbf{C T} \mathbf{p w c}$ & $\mathbf{W}_{\mathbf{o}}$ & $\mathbf{T H} \mathbf{p w c}$ \\
\hline 25108 & 2.60 & 172 & 142.86 & 447.20 & 175.75 \\
21358 & 2.60 & 172 & 121.91 & 447.20 & 175.19 \\
15893 & 2.60 & 172 & 91.38 & 447.20 & 173.92 \\
2106 & 2.60 & 172 & 14.36 & 447.20 & 146.68 \\
614 & 2.60 & 172 & 6.02 & 447.20 & 101.95 \\
460 & 2.60 & 172 & 5.16 & 447.20 & 89.11 \\
401 & 2.60 & 172 & 4.83 & 447.20 & 82.98 \\
335 & 2.60 & 172 & 4.47 & 447.20 & 75.05 \\
227 & 2.60 & 172 & 3.86 & 447.20 & 58.80 \\
199 & 2.60 & 172 & 3.71 & 447.20 & 53.73 \\
\hline
\end{tabular}

Cooking pot is also analyzed under the best case, worst case, and practical worst case scenarios. The inter arrival time is a key parameter that controls other process parameters where the critical values of work-in-process, cycle-time, and throughput are achieved. Furthermore, cycle time is found to be directly proportional to the work-in-process in all three cases. The cycle-time and throughput for best and the practical-worst-case of the cooking pot are presented in Figure 5.
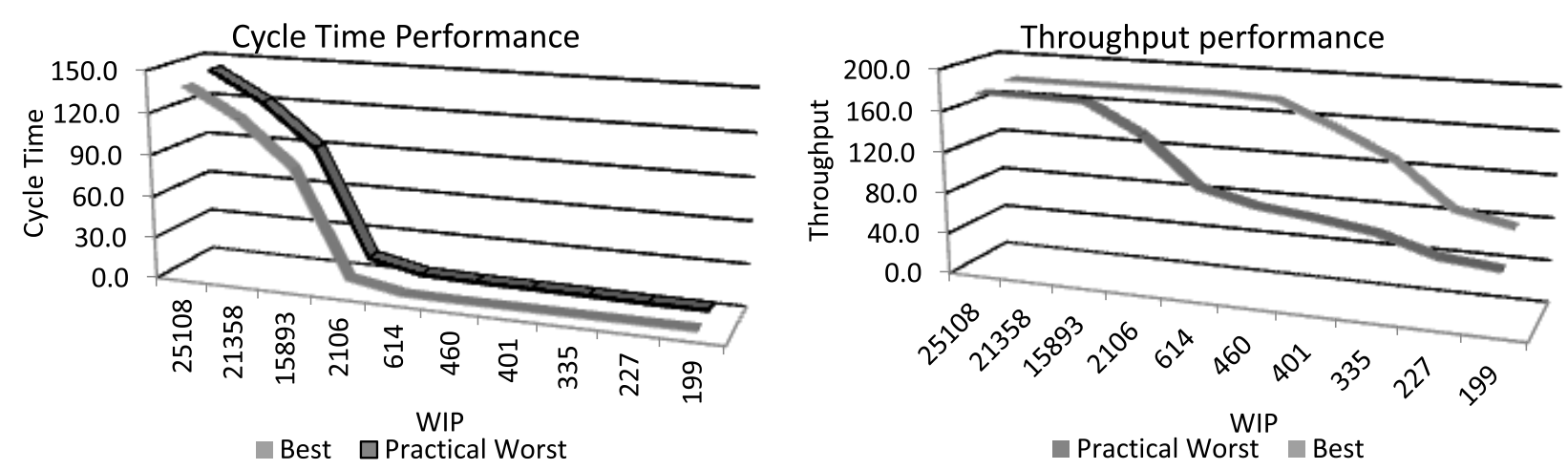

Figure 5. Cycle time and Throughput for Cooking Pot.

\section{COMPARISON OF ACTUAL AND SIMULATED RESULTS}

The difference between actual and simulated scenarios is because of the use of probability distributions in simulation. To cope with this issue, an average of the simulation readings has been taken. The results presented in Table 11 show that when value of the inter-arrival time is 20 , the plant runs for 35.48 hours. Hence, dividing the number of parts by the time taken, the rate of rejection per hour can be calculated. In case of tea pot, rate of rejection is found to be 14.7 per hour, whereas, in case of cooking pot, the rate of rejection is much less, 3.167 per hour. Actual throughput of tea pot is 96.69 and by simulation, it is 100.2. A similar trend is there in the case of cooking pot cycletime and throughput. 
Table 11. Comparison of Actual and Simulated Results.

\begin{tabular}{|c|c|c|c|c|}
\hline $\begin{array}{l}\text { S. } \\
\text { No. }\end{array}$ & Item & Description & Actual Results & $\begin{array}{c}\text { Simulation/Optimization } \\
\text { Results }\end{array}$ \\
\hline 1 & & Number of Teapots rejected & 20 & $14.70 / \mathrm{hr}$ \\
\hline 2 & Teapot & Throughput at the end of the line & 96.60 (average)/ hour & 100.20 / hour \\
\hline 3 & & Cycle time & 5.40 & 5.30 \\
\hline 4 & & Number of Cooking pots rejected & 7 & 3.17 \\
\hline 5 & Cooking pot & Throughput at the end of the line & 32.23 (average)/hour & 76.6/hour \\
\hline 6 & & Cycle time & 3.49 & 3.70 \\
\hline
\end{tabular}

\section{IMPROVEMENTS}

The improvements have been observed in terms of cycle time and throughput. The simulation model was operated at reduced inter-arrival time to observe the decrease in cycle-time. From the results shown in Figure 6, a notable decrease in cycle time has been found.

\section{Tea pot}

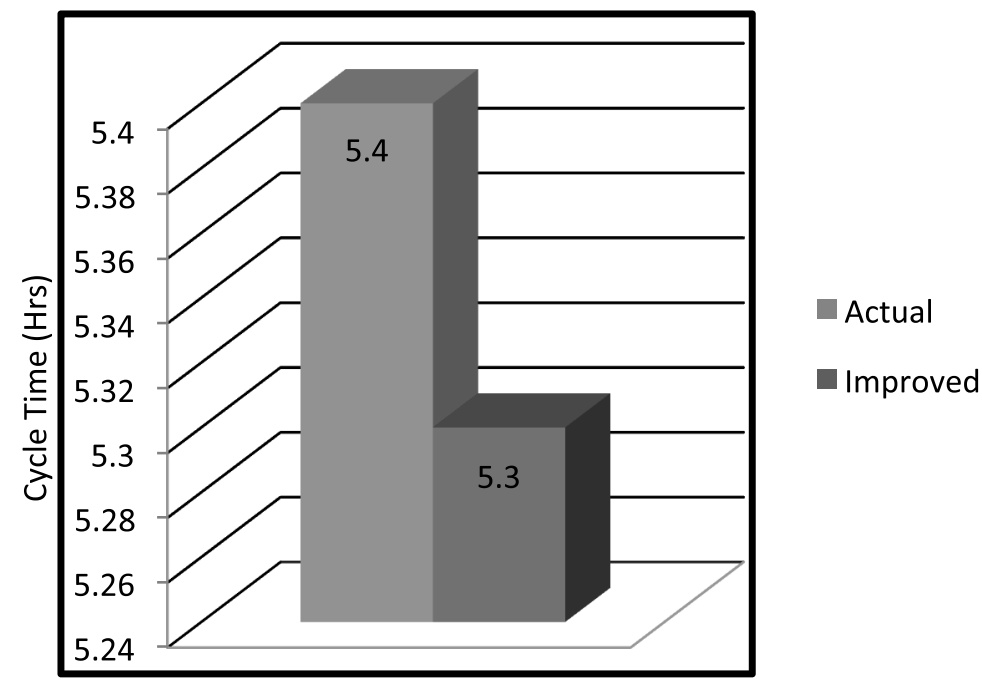

Figure 6. Cycle-time comparison (Actual vs Improved). 


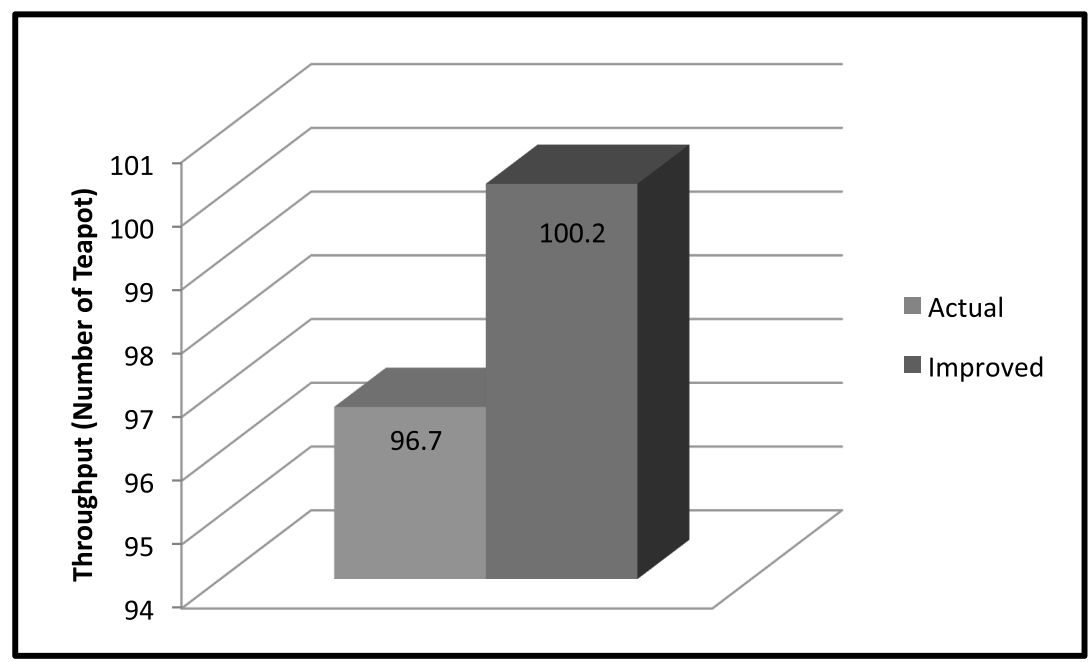

Figure 7. Throughput Comparison (Actual vs Improved).

Figure 6 shows that the cycle time has been decreased from 5.40 to 5.30 hours. Similarly, the difference in throughput is illustrated in Figure 7. From Figure 7, it can be seen that the actual throughput is 96.70 per hour; however, if down times are avoided, the throughput can be increased to $100.20 / \mathrm{hr}$.

The proposed simulation model has been developed for tea pot and cooking pot. Results obtained from the model and performance measure graphs of factory are compared with different scenarios. It has been found that the performance of the tea pot lies in good region. The improvement has been brought by decreasing the inter-arrival time from 20 minutes to 15 minutes. A decrease in inter-arrival time results in increased throughput and reduced cycle time of teapot. The model is tested with zero failure scenarios.

\section{Cooking pot}

Figure 8 shows that the cycle time has been increased from 3.49 to 3.70 hours under optimized conditions. Similarly, the difference in throughput is illustrated in Figure 9, which clearly shows that the actual throughput is 32.23 per hour; however, if down times are evaded, the throughput can be increased to 76.60 per hour.

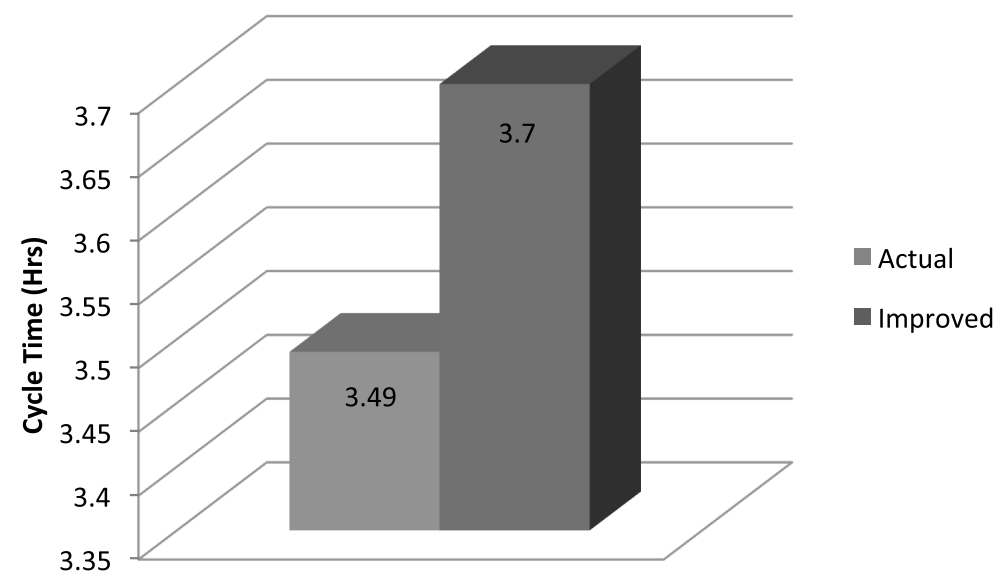

Figure 8. Cycle Time Comparison (Actual vs Improved). 


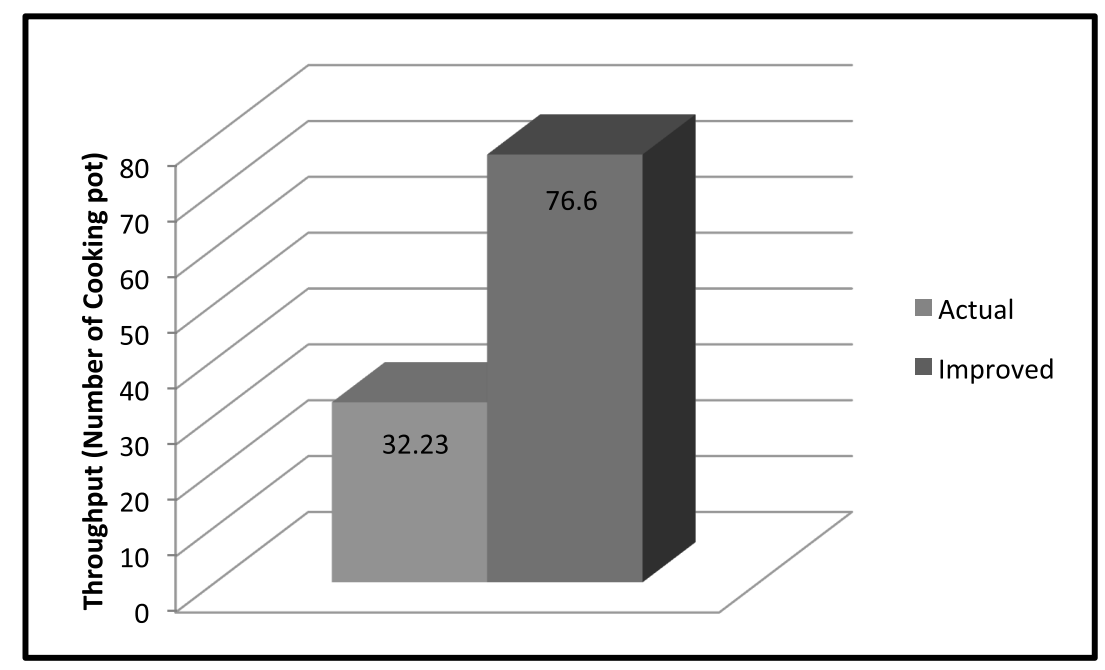

Figure 9. Throughput Comparison (Actual vs Improved).

Results obtained from the model and actual performance measuring graphs are compared under various scenarios. It has been found that the performance of the cooking pot lies in bad region. The improvement has been brought by decreasing the inter-arrival time from 20 minutes to 15 minutes. A decrease in inter-arrival time resulted in increased throughput; however, it has also been observed that there is a fractional increase in cycle time of cooking pot as shown in the Figure 8. The model is tested with zero failure scenarios.

It has been found that there is a potential for improvement in many areas of the factory. A simulation for improving factory layout and process flow can be implemented in the existing setup of the factory.

\section{CONCLUSIONS AND RECOMMENDATIONS}

A simulation based optimization model is developed for a manufacturing plant to find potential improvements without disturbing the current setup of the facility. The simulated model is verified and validated through numerous experiments. The factory has been benchmarked for 2 entities, out of which one (tea pot) is found in good region and the other (cooking pot) in bad region. The target was to optimize Throughput $(T H)$, Work-in-Process $(W I P)$, and Cycle-Time $(C T)$. Throughput of entities is notably increased, while cycle-time and work-in-process are reduced by reducing inter-arrival time. The bottleneck station of the manufacturing unit has also been detected and optimized.

The values of the input parameters are generated using Arena input analyzer. The experiments are then performed at various levels of inter-arrival time to find out the impact on Throughput (TH), Work-in-Process (WIP), and Cycletime $(C T)$. The scenarios of best, worst, and practical worst cases have also been identified to know the current position and region of the process parameters.

The comparison of the actual case with simulated model shows that the proposed setup made improvements in terms of increment in throughput $(T H)$ and decrease in cycle-time $(C T)$. The optimized results are also obtained from the simulation for the improvements in shop floor. The results show that various potential areas are there in the current setup and improvements can be made easily without disturbing the existing setup to achieve lean manufacturing. The suggested factors are inventory management, use of storage buffers, shop floor improvement, line balancing, use of semi-automated or fully automated conveyors for transportation of parts between units, preventive maintenance, and scheduled maintenance.

The proposed model of the case study can be extended to different types of products produced by the utensils manufacturing plant. Furthermore, the scope can also be extended to other various areas such as line balancing, assembly plants, discrete parts manufacturing line, automobiles parts manufacturing, and assembly plants for small and medium enterprises. 


\section{REFERENCES}

Ahmad, N., Ahmed, J., Noriah, Y. \& Nurul, H. 2012. Development of Kanban System at Local Manufacturing Company in Malaysia - Case Study, International Symposium on Robotics and Intelligent Sensors 2012 (IRIS 2012)

Ajdari, A. \& Mahlooji H. 2014. An adaptive exploration-exploitation algorithm for constructing metamodels in random simulation using a novel sequential experimental design." Communications in Statistics-Simulation and Computation 43(5): 947-968.

Amiri, M. \& Mohtashami A. 2012. Buffer allocation in unreliable production lines based on design of experiments, simulation, and genetic algorithm. The International Journal of Advanced Manufacturing Technology 62(1-4): 371-383.

Antuela, A.T. \& Stewart, R. 2012. The application of discrete event simulation and system dynamics in the logistics and supply chain context, Decision Support System 52 802-815

Barenji, A.V. \& Barenji, R.V. et al. 2016. Flexible testing platform for employment of RFID-enabled multi-agent system on flexible assembly line. Advances in Engineering Software 91: 1-11.

Catherine A., Leonardo, B.H., Philippe, B., Serge, D. \& Luc, P. 1997. A two-stage methodology for short-term batch plant scheduling: discrete-event simulation and genetic algorithm, PII: S0098-1354(97)00232-09

Chiang, K., Kuan-Ling, H., Yan-Ming, H., Wen-Jui L., Shao-Kang, H. \& Chin-An, W. 2013. Productivity of Taiwan's 1000 largest companies, Journal of Industrial and Production Engineering, 30:1, 44-53, DOI: 10.1080/10170669.2012.762059.

Chung-Ho, C., Chao-Yu, C., Chao-Chin, K. \& Michael, B.C.K. 2014. Production quantity and specification limits settings by considering specified process capability value, Journal of Industrial and Production Engineering, 31:4, 229-237, DOI: $10.1080 / 21681015.2014 .934505$

Curtis, I. \& Dimitri, M. 2012. Object-Oriented Discrete Event Simulation Modeling Environment for Aerospace Vehicle Maintenance and Logistics Process, Procedia Engineering 411721 - 1726 Conference on System engineering research, Curtis Iwata, Dimitri Mavris ,Eds.: C.J.J. Paredis, C. Bishop, D. Bodner, Georgia Institute of Technology, Atlanta, GA, March 19-22, 2013.

Dehghanimohammadabadi, M. \& Keyser T.K. 2017. Intelligent simulation: Integration of SIMIO and MATLAB to deploy decision support systems to simulation environment. Simulation Modelling Practice and Theory 71: 45-60.

Doug, C. \& Saeid, N. 2003. Application of discrete event simulation for robust system design of a melt facility, Robotics and Computer Integrated Manufacturing 19 469-477

Galankashi, M.R. \& Fallahiarezoudar, E. et al. 2016. Performance evaluation of a petrol station queuing system: A simulationbased design of experiments study. Advances in Engineering Software 92: 15-26.

Geyik, F. \& Dosdoğru, A.T. et. al. 2013. Process plan and part routing optimization in a dynamic flexible job shop scheduling environment: an optimization via simulation approach. Neural Computing and Applications 23(6): 1631-1641.

Greg Werker, A.S., John, F. \& Steven, S. 2009. The use of discrete-event simulation modelling to improve radiation therapy planning processes

James, T.L., Chien-Ming, C., Chun-Chih, C. \& Hsin-Ying, F. 2013. Simulation optimization with PSO and OCBA for semiconductor back-end assembly, Journal of Industrial and Production Engineering, 30:7, 452-460, DOI: $10.1080 / 21681015.2013 .860926$

Jong-Kwon, L. \& Ju-Jang, L. 1997. Discrete Event Modeling And Simulation For Flow Control In An Automated Highway System, PII: S0968-090X(97)00010-7

Lacksonen, T. 2001. Empirical comparison of search algorithms for discrete event simulation, Computers \& Industrial Engineering $40133 \pm 148$

Moazzami, A. \& Galankashi, M.R. et al. 2013. Simulation, modeling and analysis of a petrol station. Int Rev Model Simul (IREMOS) 6(1): 246-253.

Nurul, F.H., Mad, I.S., Nor, A.M.L., Mohamed, N.A.A. \& Nursyazwani, M.F. 2016. Lean six sigma performance improvement tool for automotive suppliers, Journal of Industrial and Production Engineering, 33:4, 215-235, DOI: $10.1080 / 21681015.2015 .1136966$

Nur, A.M., Jeng, F.C., Shahrul, K., Mohd, A.C. \& Joshua, P. 2015. Fundamental simulation studies of CONWIP in frontend 
wafer fabrication, Journal of Industrial and Production Engineering, 32:4, 232 246, DOI: 10.1080/21681015.2015.1045562

Pinto, L. \& Silva, P. et al. 2015. A generic method to develop simulation models for ambulance systems. Simulation Modelling Practice and Theory 51: 170-183.

Savsar, M. \& Al-Jawini, A. 1995. Simulation Analysis of JIT Systems, International Journal of Production Economics, 42: 67-78

Savsar, M. 1996. Effects of Kanban Withdrawal Policies and Other Factors on the Performance of JIT Systems- A Simulation Study, International Journal of Production Research, 34(10): 2879-2899

Savsar, M. \& Abdulmalek, F. 2008. Modeling of a Pull-Push Assembly Control System to Minimize Inventory and Demand Delay Costs, International Journal of Industrial Engineering, 15(1)

Spedding, T.A. \& Sun, G.Q. 1999. Application of discrete event simulation to the activity based costing of manufacturing systems, Int. J. Production Economics, 58: 289-301

Tako, A.A. \& Kotiadis, K. 2015. PartiSim: a multi-methodology framework to support facilitated simulation modelling in healthcare. European Journal of Operational Research 244(2): 555-564.

Thomas, P. \& Lars, M. 2014. Simulation-based performance assessment of master planning approaches in semiconductor manufacturing, Omega 46: 21-35

Villamizar, J.R., Coelli, F.C., Pereira W.C.A. \& Almeida R.M.V.R. (2011). Discrete-event computer simulation methods in the optimisation of a physiotherapy clinic, Physiotherapy 97: 71-77

Wright, D.B. \& Osborne, J.E. 2005. Dissociation, Cognitive Failures, and Working Memory. American Journal of Psychology 118(1): 103-114.

Yossi, B. \& Yuval, C. 2013. Minimising throughput loss in assembly lines due to absenteeism and turnover via work-sharing, International Journal of Production Research, 51:20, 6140-6151, DOI: 10.1080/00207543.2013.807374

Submitted: 05/01/2018

Revised: 22/05/2019

Accepted: 13/06/2019 


\section{تحسين الإنتاجية، والعمل تحت التشغيل والوقت المستغرق: دراسة حالة لمصنع لإنتاج الأواني محمد شفيق، محمد وقاص، خورام شهز اد، زاهد رشيد، عابد علي، محمد عويس إسلام،

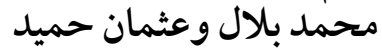 قسم الهندسة الصناعية، جامعة الهندسة، تاكسيلا للتكنولوجيا، باكستان}

\section{الخلاصة}

تطوير نماذج المحاكاة لتحسين الأداء هو أمر عصري في الصناعات التحويلية. يقدم هذا البحث نموذج محاكاة لتمات لتقييم وتحسين

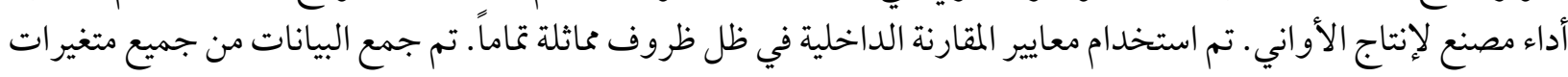

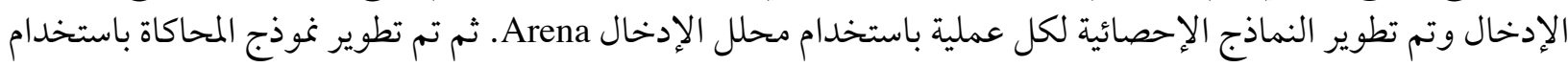

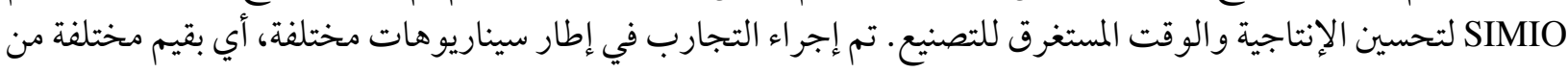

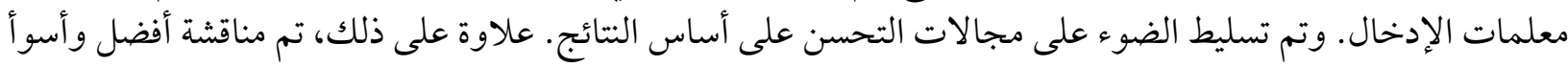

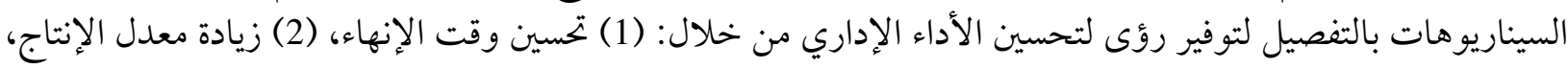
و (3) تقليل عدد الأجزاء المرفوضة دون الإخلال بالقائمة الحالية في المصنع. 